\title{
Climate change: impacts on electricity markets in Western Europe
}

\author{
Rolf Golombek • Sverre A. C. Kittelsen • \\ Ingjerd Haddeland
}

Received: 11 October 2010 /Accepted: 28 September 2011 /Published online: 23 November 2011

(C) The Author(s) 2011. This article is published with open access at Springerlink.com

\begin{abstract}
This paper studies some impacts of climate change on electricity markets, focusing on three climate effects. First, demand for electricity is affected because of changes in the temperature. Second, changes in precipitation and temperature have impact on supply of hydro electric production through a shift in the inflow of water. Third, plant efficiency for thermal generation will decrease because the temperature of water used to cool equipment increases. To find the magnitude of these partial effects, as well as the overall effects, on Western European energy markets, we use the multi-market equilibrium model LIBEMOD. We find that each of the three partial effects changes the average electricity producer price by less than $2 \%$, while the net effect is an increase of only $1 \%$. The partial effects on total electricity supply are small, and the net effect is a decrease of $4 \%$. The greatest effects are found for Nordic countries with a large market share for reservoir hydro. In these countries, annual production of electricity increases by $8 \%$, reflecting more inflow of water, while net exports doubles. In addition, because of lower inflow in summer and higher in winter, the reservoir filling needed to transfer water from summer to winter is drastically reduced in the Nordic countries.
\end{abstract}

\section{Introduction}

Climate change will have impact on supply of, and demand for, goods. For example, a change in temperature will shift demand for electricity based heating and cooling, thereby

Electronic supplementary material The online version of this article (doi:10.1007/s10584-011-0348-6) contains supplementary material, which is available to authorized users.

R. Golombek $\cdot$ S. A. C. Kittelsen $(\bowtie)$

Frisch Centre, Gaustadalléen 21, NO-0349 Oslo, Norway

e-mail: sverre.kittelsen@frisch.uio.no

I. Haddeland

Norwegian Water Resources and Energy Directorate, P.O. Box 5091 Maj., NO-0301 Oslo, Norway 
causing shifts in the equilibrium price and quantity of electricity. So far, this type of effect has received limited attention among economists; in the economics climate change literature, the main focus has been to study the impacts of imposing efficient climate policy instruments without taking into account the direct effects of climate change.

There are science studies examining the impact of climate change on hydropower (e.g., Lehner et al. 2005; Hamlet et al. 2010; Madani and Lund 2010), on thermoelectric power generation (e.g., Forster and Lilliestam 2010) and on wind power (e.g., Sailor et al. 2008; Lucena et al. 2010). These types of direct impacts of climate change will affect the equilibrium price of electricity, an issue that has typically been neglected, see the Mideksa and Kallbekken 2010 literature review of the impact of climate change on electricity markets. The purpose of the present study is to fill some of this gap by examining direct effects of climate change on electricity markets in Western Europe, and the equilibrium consequences of these effects.

There are a number of direct effects of climate change on electricity markets. In the present study we focus on three of these, excluding factors like, for example, wind conditions and water availability for cooling of power plants. First, demand for electricity is affected by temperature changes. Typically, warmer summers lead to increased demand for electricity-based cooling, whereas higher temperatures in the winter decrease demand for electric heating. While the sign of the change in seasonal demand is clear, for annual demand this is an empirical question.

Second, for hydro electric power generation, changes in precipitation and temperature have impacts on the supply of electricity through a shift in the inflow of water: both annual inflow and the distribution of inflow between summer and winter will change. These changes will have impact on hydro power production as well as on investment in reservoirs, and hence on the amount of water transferred between seasons.

Third, for thermal power generation including nuclear, average annual plant efficiency will decrease. These technologies use water to cool technical equipment, and hence higher water temperatures, reflecting higher air temperatures, will lower energy efficiency - this is the so-called Carnot effect (Carnot et al. 1890). Water temperatures may occasionally be so high that nuclear plants have to stop operating.

The contribution of this article consists of three parts. First, we contribute to the literature on impacts of climate change on hydro power. Second, we bring together the best significant estimates of the (selected) three direct effects of climate change on electricity markets. Third, and most importantly, we modify the numerical economic equilibrium model for energy markets LIBEMOD and use this to find the impact on electricity prices, production, storage and transmission of each of the three direct climate change effects as well as the net equilibrium effect of all the three direct climate effects.

Model simulations are necessary to find these equilibrium effects. Whereas the summer cooling effect suggests an increase in electricity demand, the summer inflow effect (less applicable precipitation in most countries, see discussion below) and the lower thermal efficiency effect have the opposite impact on electricity supply. All three effects put, however, upward pressure on summer electricity prices. Similarly, the winter demand effect (less heating) and the thermal efficiency effect tend to decrease winter production, whereas the inflow winter effect (more usable precipitation) has the opposite effect. The plant efficiency effect should imply higher winter prices, while lower winter prices should follow from reduced winter demand and increased winter inflow.

The main focus of LIBEMOD is the Western European energy markets. In the model, agents in each Western European country determine investment, production, trade and consumption of energy goods. A key component of the model is electricity supply-in each 
country there are a number of different electricity technologies. Profit-maximizing electricity producers determine investment in new production capacity as well as utilization of pre-existing capacities, facing technology specific constraints and a number of cost components. LIBEMOD determines all prices and quantities in the energy markets.

LIBEMOD is suitable to examine the impact of climate effects on electricity markets. First, the model contains a detailed Constant Elasticity of Substitution (CES) demand system (see e.g. Perroni and Rutherford 1995), which can be adjusted to account for changes in temperature. Second, because the modeling of hydro electric power specifies an inflow capacity of water, changes in precipitation are easy to implement in LIBEMOD. Third, the detailed modeling of electricity supply facilitates adjustments to capture the Carnot effect.

\section{Climate change effects on electricity markets}

The climatic effects of greenhouse gas emissions are primarily increases in temperature and changes in precipitation. The impact on wind is more uncertain: The main lessons from the literature are that future wind conditions in Western Europe are uncertain, and that there are no consensus estimates for change in wind conditions that are significantly different from the no change scenario (Pryor et al. 2005; Haugen and Iversen 2008 and Kjellström et al. 2011). Therefore, inclusion of a change in wind conditions would only add uncertainty to our model, and we decided to disregard changes in wind conditions. Moreover, the uncertainty about cost estimates for wind power is so high that we cannot use LIBEMOD's output with respect to wind power investments. Hence, in the present study wind power investments are exogenous.

The climatic effects we attempt to model below are:

a. changes in demand for electricity due to changes in the need for heating and cooling,

b. changes in supply of hydropower due to changes in precipitation and temperature, and

c. changes in thermal power supply due to warmer cooling water and therefore lower plant efficiency.

Emissions of greenhouse gases have major damaging effects in the long run, while the short-run effects are minor. This suggests focusing attention on a year several decades ahead, for example, 2100. On the other hand, not much is known about the energy markets in 2100. There is no obvious solution to this trade-off. In order to illustrate the impact of climate change on electricity markets, we use a pedagogical tool, namely to postulate that the average climate in a future time period (2070-2099) materializes in a much earlier year (2030). The year 2030 is far enough into the future to enable optimal investments to change production and transport capacities, but short enough that the economic and political structure can reasonably be expected to continue on the historical trends presently observed. The resulting scenarios and simulations must therefore be carefully interpreted; they are not predictions of actual behavior, but are comparative static simulations of the effects of a climate change on a power system that has had time to adapt.

Below, climate change effects for 2070-2099, for simplicity referred to as 2085, build on the IPCC scenario A1b, see IPCC (2007). This is the most referred emission scenario from IPCC (2007), with a projected global warming of $2.8^{\circ} \mathrm{C}$ until the end of this century. While IPCC (2007) reports results from global climate model simulations, these must be disaggregated to find climate effects for each Western European country which are needed in our analysis. Downscaling of temperature was performed using an empirical-statistical 
method based on climate model results, ERA40 re-analysis data (Uppala et al. 2005), and weather station observations, see Benestad (2005, 2008a). The downscaling was based on 20 global climate models described in the IPCC fourth assessment report (Meehl et al. 2007). The estimated multi-model mean temperatures for the period 2071-2100 were used. The complete list of the global circulation models and runs included in this analysis can be found in Table 5 in Benestad (2008b).

\subsection{Demand for electricity}

The demand effect of a warmer climate operates primarily through the need for increased cooling during the summer, and less heating during the winter. These effects are picked up by the annual number of Cooling-Degree-Days (CDD) and Heating-Degree-Days (HDD): Let $T_{d}$ be the average daily temperature $\left({ }^{\circ} \mathrm{C}\right)$ on day $d$. Then $T_{d}-22$ (if positive) is the number of degrees that the average temperature exceeds $22^{\circ} \mathrm{C}$ on day $d$. When this (positive) number is summed over all days in a year for which $T_{d}$ exceeds $22^{\circ} \mathrm{C}$, one obtains $\mathrm{CDD} ; \sum_{d=1}^{365} \operatorname{Max}\left(0, T_{d}-22\right)$. HDD is the corresponding sum of temperatures lower than $18^{\circ} \mathrm{C} ; \sum_{d=1}^{365} \operatorname{Max}\left(0,18-T_{d}\right)$.

According to the Mideksa and Kallbekken (2010) review, the sign of the heating and cooling effects on electricity demand seem to be consistent across studies, but with a wide variation on the magnitude of the estimates, see, for example, Baxter and Calandri (1992), Aroonruengsawat and Auffhammer (2009) and Isaac and van Vuuren (2009) and De Cian et al. (2007). Here we build on Eskeland and Mideksa (2009), which used an instrumental variables approach to account for the endogeneity of prices. This is an econometric study of residential demand for electricity using a panel of Western European countries. Using a fixed-effects regression model, this study allows for country differences in the response to temperature changes. As is common in the literature, they include the annual number of CDD and HDD among the independent variables, and find small but significant estimates of the effect of CDD and HDD on per capita electricity consumption.

The Eskeland and Mideksa study has also calculated CDD and HDD separately for each Western European country based on city-specific data in Benestad (2008a). They found that the climate change from 2000 to 2085 increases CDD by 121 days (88\%) and decreases HDD by 712 days (28\%) for Western Europe as a whole, see Table 1 in Online Resource 1.

Combining the estimated coefficients of CDD and HDD from Eskeland and Mideksa (2009) with the calculated changes in CDD and HDD because of climate change from 2000 to 2085, we find that, cet. par., demand for electricity in Western Europe increases by $3.6 \%$ from 2000 to 2085 due to increased cooling needs, but decreases due to lower heating needs by $7.3 \%$. The net direct effect, before the feedback from the model equilibrium changes of supply and prices, is a decrease in annual demand in Western Europe by $3.7 \%$.

Figure 1 shows electricity demand in the base year 2000 and calculated direct changes in demand with 2085 climate because of more cooling and less heating. Demand changes are not uniform across countries. As expected, the Northern European countries decrease their heating demand, but there is almost no increase in their cooling demand since even with a warmer climate there are few days with an average temperature above $22^{\circ} \mathrm{C}$. This is mostly reversed in Southern European countries where the increase in cooling demand clearly dominates over the decrease in heating demand. Because heating is needed mainly in winter and cooling mainly in summer, these demand changes are imposed on LIBEMOD in the corresponding season only. The effect of climate change on demand in the model is a shift from northern to southern countries, and a shift from winter to summer. 


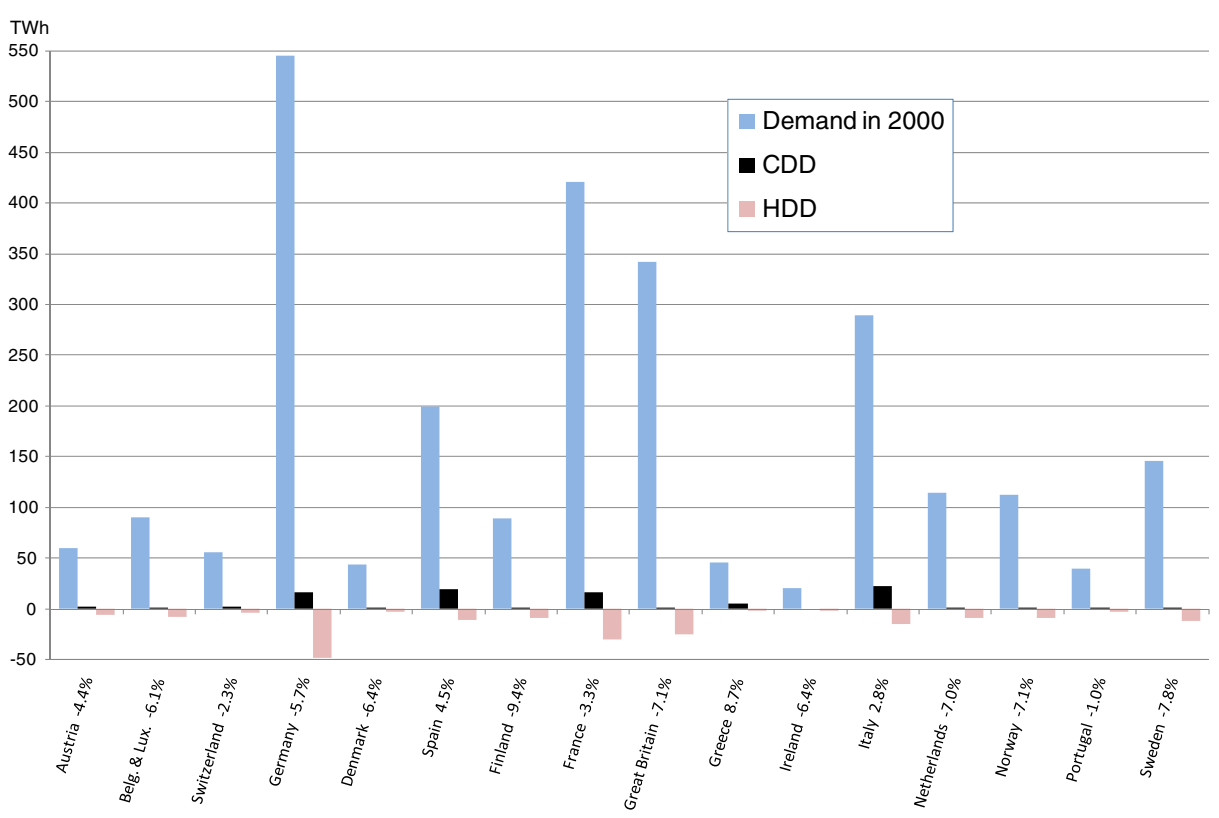

Fig. 1 Electricity demand in the base year 2000 and calculated direct changes in demand with 2085 climate because of more cooling (CDD) and less heating (HDD). Percentage numbers are total direct changes from both cooling and heating effects

\subsection{Inflow of water}

Projected changes in runoff have been estimated by the VIC hydrology model (Liang et al. 1994). The model was run at $0.5^{\circ}$ spatial resolution for the baseline period (1961-1990), using CRU (Climate Research Unit of the University of East Anglia) meteorological input data (Mitchell and Jones 2005). For the projection period (2070-2099), air temperature and precipitation data from two global circulation models (GCM) run under the A1b emission scenario were used, the Hadley Center Coupled Model (HadCM3, Gordon et al. 2000) and the Max Planck Institute model ECHAM5 (Roeckner et al. 2006). To create the meteorological input data, the 'delta change approach' was used: the monthly changes in precipitation and temperature between baseline and projection were calculated, and these changes were imposed on the CRU data. The meteorological data for the baseline and the projection periods were created similarly to the method used by Adam et al. (2009). The results for each run are given as a percentage change in runoff between baseline and future periods for each country and for each season; summer (April 1 - September 30) and winter (October 1 - March 30).

In hydropower production, runoff is only useable to the extent that it reaches run-of-river power plants or the reservoirs; in the latter case the energy content depends on the altitude difference between reservoir and power station. For Norway, a detailed model ("samkjøringsmodellen") has been used to calculate seasonal inflow measured in energy content of usable water (TWh) that would result from the 2,085 runoffs while keeping the 2000 power system infrastructure. For other countries, we have assumed that changes in inflow are proportional to country-average changes in runoff in each season.

Figure 2 shows inflow by country and season, where the 2,085 numbers reflect direct effects of climate change had the hydropower capacities been kept unchanged from 2000 . 


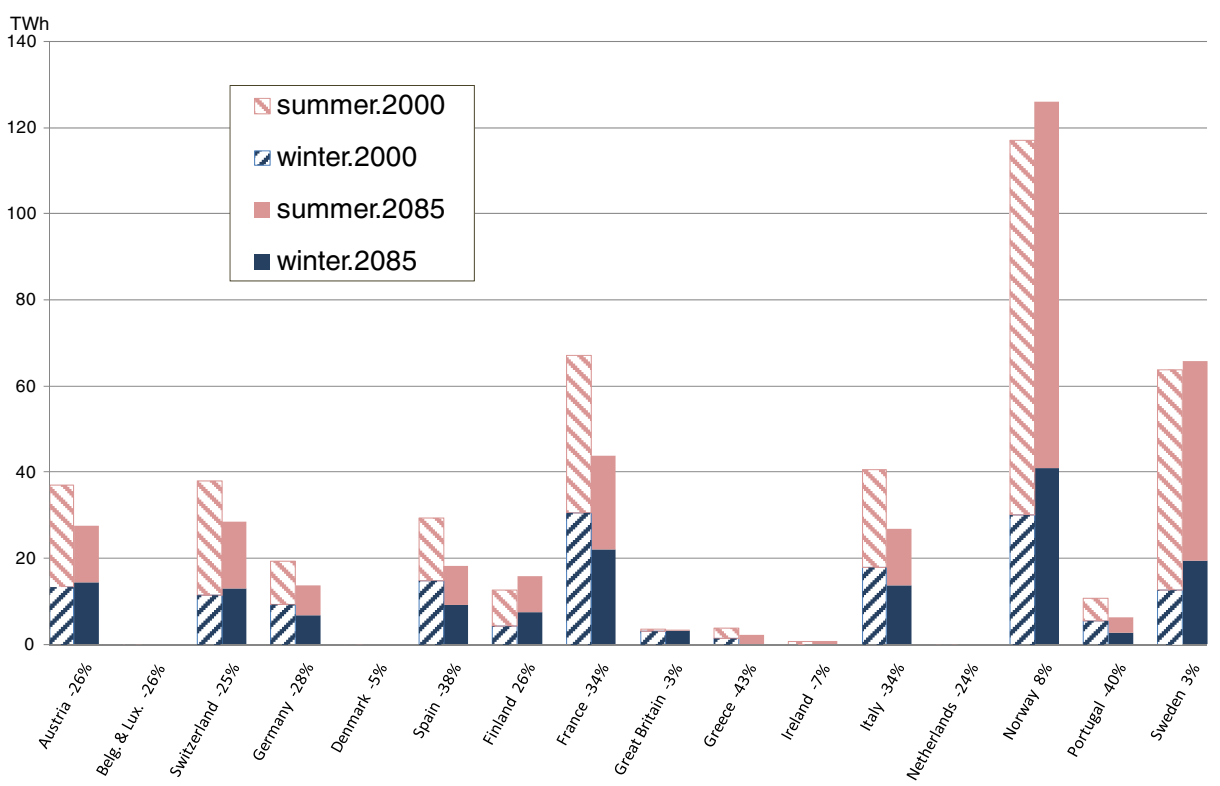

Fig. 2 Seasonal inflow in 2000 and 2085 with the 2000 power system infrastructure. Normal year production for 2000 based on Nordel (2001) and IEA (1998, 2002). Percentage numbers are total annual direct changes

Annual inflow in Sweden, Finland and Norway increases relative to 2000, whereas there is a decline in Southern European countries. The net effect is a $15 \%$ decrease in inflow (and thereby production) for the group of model countries.

In the Nordic and Alpine countries, most of the inflow is received in the summer because winter precipitation falls as snow and is only usable for electricity production when it melts. These countries all expect an increase in winter inflow in 2,085, mostly due to higher temperatures. In Southern Europe, summer inflow decreases as a result of both less precipitation and higher temperatures. The main pattern is a shift in inflow from Southern to Northern Europe, and from summer to winter, exactly mirroring the demand changes.

\subsection{The Carnot effect}

The efficiency of thermal power plants depends on the temperature of the water used for cooling; the hotter the water, the lower is efficiency. Atmospheric warming and changes in river flow are expected to affect river temperatures; see, for example, Mohseni et al. (1999), Mantua et al. (2010) and van Vliet et al. (2011).

Thermal efficiency is in theory linearly dependent on the temperature of the cooling water or cooling air, and thus the average efficiency of thermal plants will be reduced because of climate change - usually referred to as the Carnot effect. Under intense heat waves, nuclear plants may even need to close for safety reasons, this happened in France, Germany and Spain in 2006, and later in Sweden. The Carnot effect means that for the same amount of inputs, output is reduced. However, the Carnot effect will in general lead to a change in the amount of inputs through the market mechanism. 
The first step in identifying the Carnot effect is to estimate the temperature changes. Benestad (2009) has estimates for 2,085 quarterly temperatures for the same cities as in Benestad (2008a). We have aggregated these to the seasons and countries in LIBEMOD; we find that the average 2,085 temperature (relative to 2000 ) increases by $3.0^{\circ} \mathrm{C}$ in summer and $2.8^{\circ} \mathrm{C}$ in winter.

The Mideksa and Kalbekken literature review found few studies that quantified the effect of temperature increase on thermal power efficiency. Yet, some studies are available; building on Durmayaz and Sogut (2006), Linnerud et al. (2009, 2011), and taking into account that the effect is not linear in temperature change, we obtain that thermal efficiency in 2085 is reduced by 1.8 (1.7) percent in summer (winter) in fossil plants, and reduced by 2.4 (2.3) percent in nuclear plants. Because plant efficiency differs in our numerical model LIBEMOD, the Carnot effect will be (slightly) different across technologies and countries. Note that the Carnot estimates are uncertain. They have been estimated on small samples (this is in particular the case for fossil fuel plants), and adaptation strategies of power producers, for example, installing water pumps or relocate, have not been taken into account. Still, we believe the Carnot effect should be included in the analysis.

What is the direct impact of the Carnot effect of the 2085 climate, keeping the fuel use constant at year 2000 level? In the winter, the temperature increases are greatest in Northern Europe, for example, $4.9^{\circ} \mathrm{C}$ in Finland versus $2.4^{\circ} \mathrm{C}$ in Italy, see Fig. 3, suggesting that the supply reduction is greatest in Northern Europe. Summer temperature differences are smaller, ranging from $2.4^{\circ} \mathrm{C}$ in Great Britain to $3.7^{\circ} \mathrm{C}$ in Spain, and hence the shifts in summer supply do not differ that much between countries. Because fossil plants are less common in Northern Europe, there is a small tendency that, cet. par., the reduction as a share of total electricity supply is smallest in the north. Overall, the

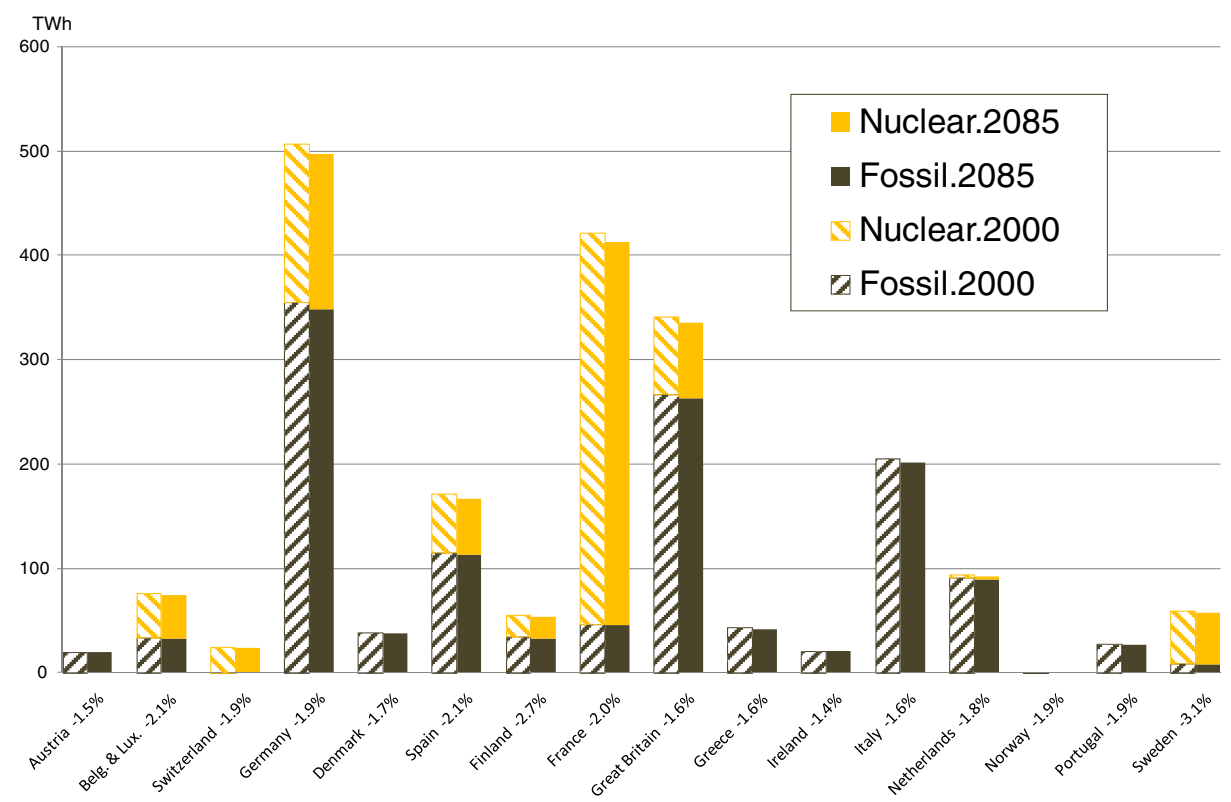

Fig. 3 Direct climate effect on thermal electricity production in 2000 and 2085 with the 2000 capacities and utilizations. Percentage numbers are direct effects for total thermal production 
unambiguous effect is to reduce supply of electricity, while geographical and seasonal patterns are weak.

\section{LIBEMOD}

We use the numerical model LIBEMOD to find the equilibrium consequences of the three direct effects of climate change on electricity markets. LIBEMOD is an economic simulation model of the Western European energy industry, see Aune et al. (2008). Its main focus is on the electricity and natural gas markets in Western Europe, but it also covers global markets for coal and oil. The model distinguishes between model countries - each of 16 Western European countries - and exogenous countries/regions.

In each model country there is production of energy, trade in energy and consumption of energy, as well as investment in energy infrastructure. LIBEMOD has seven energy goods coking coal, steam coal, lignite, natural gas, oil, biomass and electricity. Natural gas and electricity are traded between model countries. Coking coal, steam coal and oil are traded in global markets, whereas lignite and biomass are traded in domestic markets only.

Production of energy takes place in all countries. Typically, in a model country there is extraction of some fossil fuels, production of bio mass and production of electricity. Trade in natural gas/electricity requires gas pipes/electricity lines running between countries taking part in this trade. At each point in time, these capacities are given, but can be expanded through investment.

Energy is transported and distributed to the users at costs that differ according to user group and energy good. There are four groups of users; power producers (demand a fuel as an input), households (including services), industry and transport. For the latter three groups (end-users), demand is derived from a nested CES utility function with five levels. In particular, we allow for substitution possibilities between electricity consumption in summer and winter (season), and electricity consumption between day and night. The CES demand system has been adjusted to account for the demand effect of climate change, see Section 2.1.

LIBEMOD offers a detailed description of production of electricity, using a number of power technologies: steam coal, lignite, gas, oil, reservoir hydro, run-of-river hydro, pumped storage, nuclear, waste, biomass and wind. Base year capacities (from 2000) are depreciated over time, but if profitable there will be investments in new production capacities. Not all technologies are available in every country.

For each type of electricity technology and country, efficiency typically varies across power plants. In particular, the distributions of efficiencies reflect the Carnot effect, see Section 2.3. Electricity producers face a number of cost components. Several of these are linked to capacities and technical constraints faced by power producers. Some of the constraints are common for all technologies, while others are technology specific. For example, there are three technology-specific capacities for reservoir hydro; inflow capacity (collecting water in a "catchment" area and transporting the water to the reservoir), reservoir storage capacity and electricity generation capacity (power). An electricity producer maximizes profits subject to the technical constraints. This leads to operating rules, as well as decision rules for optimal investments.

LIBEMOD determines all energy quantities - investment, production, trade and consumption - and all prices for all energy goods (all fossil fuels, electricity and biomass), both producer prices and end-user prices. In addition, the model calculates emissions of carbon by sectors and countries. For a more detailed description of LIBEMOD, including data sources and calibration, see Aune et al. (2008). 


\section{Results}

\subsection{Base year climate}

Both prior to, and after, imposing the climate change effects in 2030, we assume that all model countries have a climate policy, here specified as a uniform price of $\mathrm{CO}_{2}$ of USD 50. Of course, the partial effect of imposing such a carbon price - prior to imposing climate change - is to reduce carbon emissions in 2030 (by $28 \%$ in the model countries), mainly through decreased use of coal in coal-fired power plants (by 61\%). Increased costs of using fossil fuels raise electricity prices significantly, for example, the average price received by electricity producers in the model countries at the plant site (the producer price) increases by $75 \%$. For country-specific effects prior to and after climate change, see Table 2 in Online Resource 1.

\subsection{Price effects}

In Fig. 4, for each group of (five) bars the bar most to the left shows the change in producer price of electricity before we impose climate change effects but after a carbon price of USD 50 has been imposed ("Base year climate"). For a given carbon price of USD 50, the second bar from the left shows the pure demand effect, the third bar from the left shows the pure inflow effect, the fourth bar from the left shows the Carnot effect, and finally the bar most to the right shows the total effect on the producer price of all three climate effects.

The first group of bars shows the effect for Western Europe, whereas the other groups show the effects for selected countries. The total effect of a change in climate on the producer price in Western Europe is an increase of only 1\% (For country-specific effects, see Online Resource 1). This average annual increase reflects that the average producer

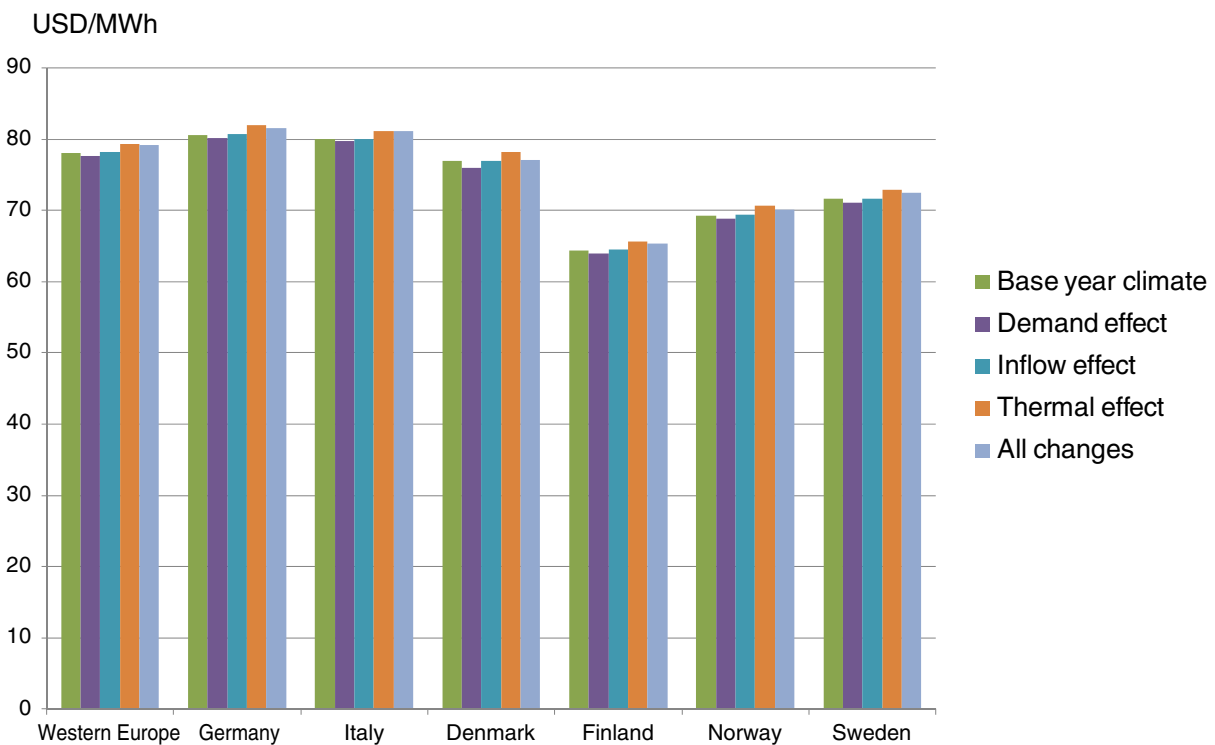

Fig. 4 Electricity producer prices in Western Europe and selected model countries in 2030 with base year climate, each partial climate effect and all climate effects 
price on winter days has not changed, whereas the average price on winter nights, summer days and summer nights all increase by $2 \%$. For each model country, the average annual producer price of electricity increases by either 1 or $2 \%$. Further, for each of the three partial effects, seasonal day and night prices change by less than $2 \%$. Hence, the price effects of climate change are negligible.

\subsection{Quantity results}

As a result of all three direct climatic effects, total production of electricity in the model countries decreases by $4 \%$, mainly reflecting the demand effect, see Fig. 5. The inflow effect hardly changes total production of electricity, whereas the Carnot effect decreases production by only $1 \%$, mainly reflecting lower production of gas power and nuclear.

As seen from Fig. 5, the total effect on electricity production differs between countries. In Germany production decreases significantly, in Sweden production is roughly unchanged, whereas production increases in Italy and Norway. There are several reasons for these differences. First, shifts in seasonal demand differ between countries, reflecting, for example, that in some countries there is no need for cooling because it never gets hot. Second, there are countries where a substantial share of the heating is based on electricity, whereas in most other countries heating is mainly based on fossil fuels.

An additional reason for country differences in the response to climate change is that the mix of electricity technologies differs; see Table 3 in Online Resource 1. In most countries, thermal power covers most of the electricity generation. Yet, in some countries, particularly Norway, but also Sweden and to some extent Austria, Finland and Switzerland, hydro has a substantial market share, and hence in these countries the inflow effect is important, while the Carnot effect may not be that important. To take one example, total hydropower production decreases by $16 \%$ because of lower annual inflow in the model countries; while
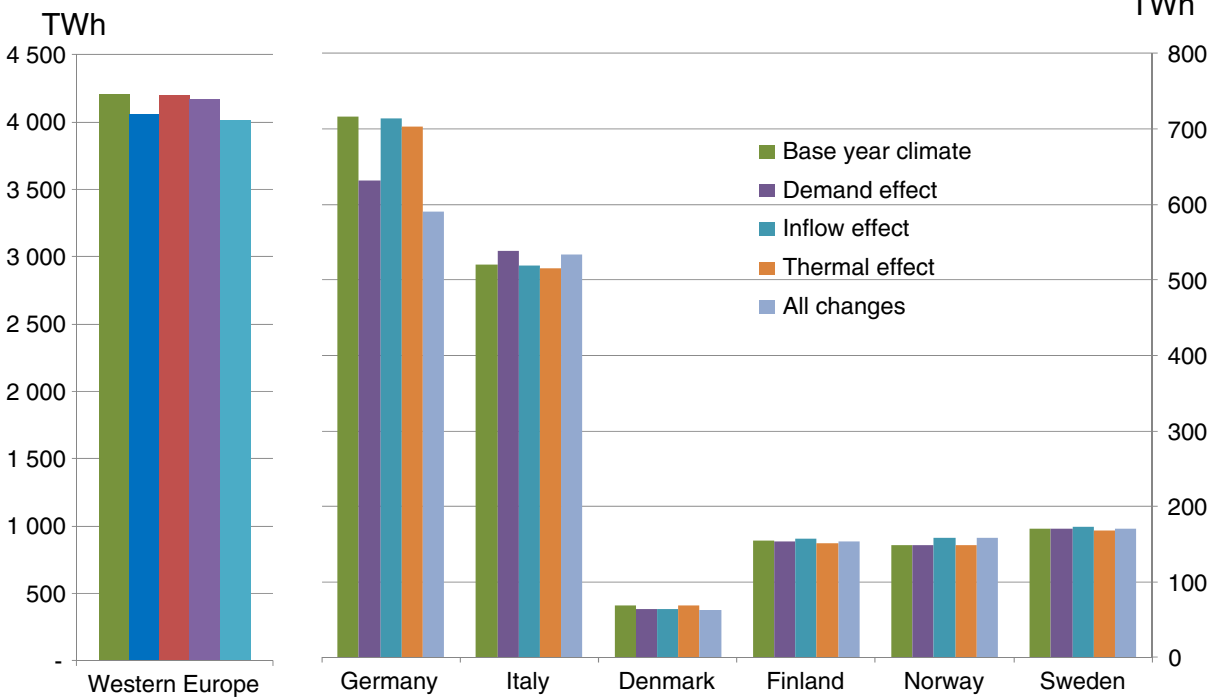

Fig. 5 Electricity production in Western Europe (left axis) and selected countries (right axis) in 2030 with base year climate, each partial climate effect and all climate effects 
production of hydro increases by $8 \%$ in the Nordic countries, in most other countries hydro electric production decreases because of the inflow effect.

\subsection{Trade effects}

Because the impacts on electricity prices differ across countries, there is potential for more trade in electricity. Electricity will be exported from high price countries to low price countries if the price differential exceeds cost of transmission, subject to transmission capacity being available. For significant price differences between countries, expansion of international transmission capacity becomes profitable, which will increase international trade and lower the international price differentials.

In our study the reported effects on electricity production are in general small, and hence trade does not change much. There is, however, a significant effect on electricity trade in Northern Europe: Without climate change, all Nordic countries are net exporters of electricity, and net exports from the Nordic countries are roughly $10 \%$ of Nordic electricity supply. With all climate effects, Nordic net export doubles, reflecting that the electricity transmission capacity at the border of the Nordic countries and continental Europe has increased by around $80 \%$, mainly due to the demand effect $(60 \%)$, but to some extent also due to the inflow effect (20\%), see Fig. 6, panel a.

The increase in electricity trade reflects that climate effects differ between the Nordic countries and continental Europe. In the Nordic countries reservoir hydro has a substantial market share. Typically, the reservoir is used to transfer water from summer to winter, that is, water in the reservoir is scarcer in the winter than in the summer. In the Nordic countries, winter inflow of water increases substantially, summer demand does not increase much because cooling is hardly an issue, and winter demand decreases. These factors imply that less water is transferred from summer to winter in the Nordic countries, see Fig. 6, panel b,
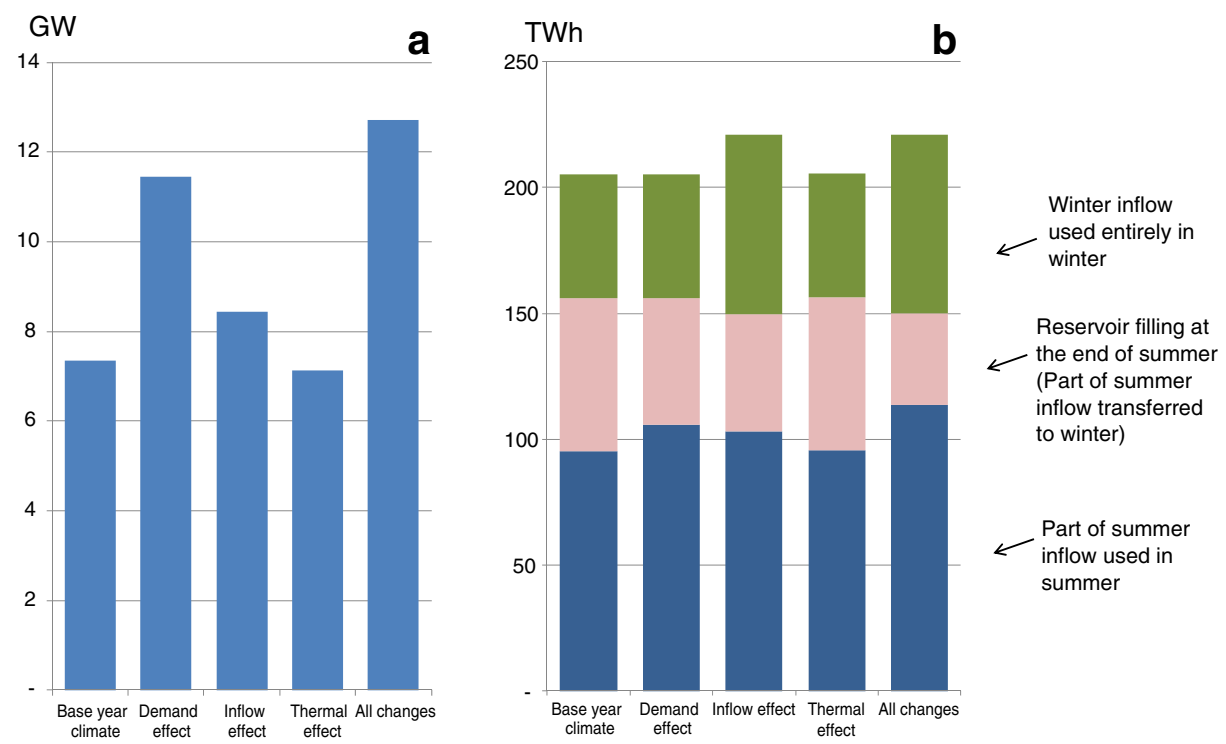

Fig. 6 Panel a: Transmission capacity between Nordic countries (Denmark, Finland, Norway and Sweden) and Continental Europe. Panel b: Hydroelectricity production in the Nordic countries by inflow and season. 2030 with base year climate, each partial climate effect and all climate effects 
while more electricity is exported from the Nordic countries in summer to satisfy increased cooling demand in Continental Europe. Hence, in the Nordic countries a smaller share of the reservoir is utilized. With less transfer of water from summer to winter, production of hydro in the Nordic countries increases in the summer (by 19\%), whereas there is a minor decrease in winter hydro production.

\section{Conclusions}

In the LIBEMOD model of the energy markets of Western Europe, the expected climate changes are likely to have a small impact on electricity prices and production. We find that each of the three partial effects examined in the present paper changes the average electricity producer price by less than $2 \%$, while the net effect is an increase in the average producer price of only $1 \%$. Similarly, the partial effects on total electricity production are small, and the net effect is a decrease of $4 \%$.

The greatest effects of climate change are found for those Nordic countries with a large market share for reservoir hydro. In these countries total annual production increases by $8 \%$, reflecting an expected increase in inflow of water. A substantial part of the increase in Nordic production is exported; climate change doubles net exports of electricity from the Nordic countries, while the optimal reservoir capacity is radically reduced.

Finally, throughout this study we have assumed a common uniform price of $\mathrm{CO} 2$ emissions of USD 50. A topic for future research is to analyze how different international climate agreements and climate instruments - sector neutral as well as sector-specific - may have impact on the electricity markets under future climate conditions.

Acknowledgement Earlier versions of this paper were presented at the national meeting for Norwegian economists, the Norwegian Ministry of Oil and Energy, and at the Nordic Energy, Environmental Constraints and Integration (NEECI) Workshop. We thank the participants, as well as the anonymous journal reviewers, for their very constructive comments. We will also thank Jennifer C. Adam at Washington State University for making the meteorological input data for the VIC model available. Research support from the Research Council of Norway under the program NORKLIMA is gratefully acknowledged. Parts of this research were undertaken in cooperation with the Global Water System Project (GWSP) and the European Union (FP6) funded Integrated Project WATCH (contract 036946).

Open Access This article is distributed under the terms of the Creative Commons Attribution Noncommercial License which permits any noncommercial use, distribution, and reproduction in any medium, provided the original author(s) and source are credited.

\section{References}

Adam JC, Hamlet AF, Lettenmaier DP (2009) Implications of global climate change for snowmelt hydrology in the twenty-first century. Hydrol Process 23:962-972

Aroonruengsawat A, Auffhammer M (2009) Impacts of climate change on residential electricity consumption: evidence from billing data. Paper From: California Climate Change Center, CEC-5002009-018-D.

Aune FR, Golombek R, Kittelsen SAC, Rosendahl KE (2008) Liberalizing European energy markets: an economic analysis. Edward Elgar.

Baxter LW, Calandri K (1992) Global warming and electricity demand. Energy Policy 20:233-244

Benestad RE (2005) Climate change scenarios for northern Europe from multi-model IPCC AR4 climate simulations. Geophys Res Lett 32:L17704. doi:10.1029/2005GL023401 
Benestad RE (2008a) Heating degree days, cooling degree days and precipitation in Europe. Analysis for the CELECT-project. met.no Report 4/2008 CLIMATE.

Benestad RE (2008b) Downscaled regional Norwegian temperature and precipitation series Analysis for Statnett and CES, met.no Report 7/2008 CLIMATE.

Benestad RE (2009) Re-calculation of local climate scenarios. met.no note 15/2009.

Carnot S, Thurston RH (editor and translator) (1890) Reflections on the motive power of heat and on machines fitted to develop that power. Wiley, New York

De Cian E, Lanzi E, Roson R (2007) The impact of temperature change on energy demand: a dynamic panel analysis. Working Papers 2007.46, Fondazione Eni Enrico Mattei.

Durmayaz A, Sogut OS (2006) Influence of cooling water temperature on the efficiency of a pressurizedwater reactor nuclear-power plant. Int J Energy Res 30:799-810

Eskeland GS, Mideksa TK (2009) Climate change adaption and residential electricity demand. CICERO working paper 01.

Forster H, Lilliestam J (2010) Modeling thermoelectric power generation in view of climate change. Reg Environ Change 10:327-338

Gordon C, Cooper C, Senior CA, Banks H, Gregory JM, Johns TC, Mitchell JFB, Wood RA (2000) The simulation of SST, sea ice extents and ocean heat transports in a version of the Hadley Centre coupled model without flux adjustments. Clim Dyn 16:147-168

Hamlet AF, Lee SY, Mickelson KEB, Elsner MM (2010) Effects of projected climate change on energy supply and demand in the Pacific Northwest and Washington State. Clim Change 102:103-128

Haugen JE, Iversen T (2008) Response in extremes of daily precipitation and wind from a downscaled multimodel ensemble of anthropogenic global climate change scenarios. Tellus A 60:411-426

IEA (1998) Electricity information 1997. OECD/IEA, Paris

IEA (2002) Electricity information 2002. OECD/IEA, Paris

IPCC (2007) Climate change 2007: The physical science basis. Contribution of Working Group I to the Fourth Assessment Report of the Intergovernmental Panel on Climate Change. In: Solomon S, Qin D, Manning M, Chen Z, Marquis M, Averyt KB, Tignor M, Miller HL (eds) Cambridge University Press, Cambridge, United Kingdom and New York, NY, USA.

Isaac M, van Vuuren DP (2009) Modeling global residential sector energy demand for heating and air conditioning in the context of climate change. Energy Policy 37:507-521

Kjellström E, Nikulin G, Hansson U, Strandberg G, Ullerstig A (2011) 21st century changes in the European climate: uncertainties derived from an ensemble of regional climate model simulations. Tellus A 63:2440

Lehner B, Czischb G, Vassoloa S (2005) The impact of global change on the hydropower potential of Europe: a model-based analysis. Energy Policy 33:839-855

Liang X, Lettenmaier DP, Wood EF, Burges SJ (1994) A simple hydrologically based model of land surface water and energy fluxes for GSMs. J Geophys Res 99:14415-14428

Linnerud K, Mideksa TK, Eskeland GS (2009) The impact of climate change on thermal power supply. Manuscript, CICERO

Linnerud K, Mideksa TK, Eskeland GS (2011) The impact of climate change on nuclear power supply. The Energy J 32(1):149-168

Lucena AFP, Szklo AS, Schaeffer R, Dutra RM (2010) The vulnerability of wind power to climate change in Brazil. Renew Energ 35:904-912

Madani K, Lund JR (2010) Estimated impacts of climate warming on California's high-elevation hydropower. Clim Change 102:521-538

Mantua N, Tohver I, Hamlet A (2010) Climate change impacts on streamflow extremes and summertime stream temperature and their possible consequences for freshwater salmon habitat in Washington State. Clim Change. doi:10.1007/s10584-010-9845-2

Meehl GA, Stocker TF, Collins WD et al (2007) Global climate projections. In: Solomon S, Qin D, Manning M, Chen Z, Marquis M, Averyt KB, Tignor M, Miller HL (eds) Climate change 2007: The physical science basis. Contribution of Working Group I to the Fourth Assessment Report of the Intergovernmental Panel on Climate Change. Cambridge University Press, Cambridge, United Kingdom and New York, NY, USA

Mideksa TK, Kallbekken S (2010) The impact of climate change on the electricity market: a review. Energy Policy 38:3579-3585

Mitchell TD, Jones PD (2005) An improved method of constructing a database of monthly climate observations and associated high resolution grids. Int J Clim 25:693-712

Mohseni O, Erickson TR, Stefan HG (1999) Sensitivity of stream temperatures in the United States to air temperatures projected under a global warming scenario. Water Resour Res 35:3723-3733

NORDEL (2001) Annual report 2000. Nordel, Oslo 
Perroni C, Rutherford TF (1995) Regular flexibility of nested CES functions. Eur Econ Rev 39:335-343

Pryor SC, Barthelmie RJ, Kjellström E (2005) Potential climate change impact on wind energy resources in northern Europe: analyses using a regional climate model. Clim Dyn 25:815-835

Roeckner E, Brokopf R, Esch M, Giorgetta M, Hagemann S, Kornblueh L, Manzini E, Schlese U, Schulzweida U (2006) Sensitivity of simulated climate to horizontal and vertical resolution in the ECHAM5 atmosphere model. J Clim 19:3771-3791

Sailor D, Smith M, Hart M (2008) Climate change implications for wind power resources in the Northwest United States. Renew Energ 33:2393-2406

Uppala SM, Kallberg PW, Simmons AJ et al (2005) The ERA-40 re-analysis. Q J Roy Meteor Soc 131:2961-3012

Van Vliet MTH, Ludwig F, Zwolsman JJG, Weedon GP, Kabat P (2011) Global river temperatures and the sensitivity to atmospheric warming and changes in river flow. Water Resour Res 47:W02544. doi:10.1029/2010WR009198 